\title{
Produção de Matéria Seca e Qualidade do Capim-Elefante (Pennisetum purpureum Schum.) Cultivar Roxo em Diferentes Idades de Corte ${ }^{1}$
}

\author{
José Leite de Queiroz Filho ${ }^{2}$, Divan Soares da Silva ${ }^{2}$, Inaldete Soares do Nascimento ${ }^{3}$
}

\begin{abstract}
RESUMO - Este trabalho foi realizado para avaliar a produção total de matéria seca (MS), a relação folha/colmo, a porcentagem de folhas e de colmos e o valor nutritivo do capim-elefante (Pennisetum purpureum Schum.) cultivar Roxo, submetido a quatro idades de corte (40, 60, 80 e 100 dias), no período de julho de 1994 a dezembro de 1995, no Brejo Paraibano. O plantio foi realizado em parcelas de 3,0 x 5,0 m, em um espaçamento de 0,70 x 0,80 m entre covas, em delineamento inteiramente casualizado com quatro repetições. A produção total de MS aumentou com os intervalos de cortes (comportamento quadrático), atingindo produção de 30,9 t/ha aos 100 dias. A porcentagem de folhas e a relação folha/colmo diminuíram, enquanto a porcentagem de colmos aumentou, linearmente com o aumento da idade entre os cortes. Houve diminuição nos teores de proteína bruta e conteúdo celular, enquanto os teores de fibra em detergente neutro e fibra em detergente ácido aumentaram linearmente, à medida que se aumentou a idade entre os cortes.
\end{abstract}

Palavras-chave: porcentagem de folha e de colmo, relação folha/colmo, valor nutritivo

\section{Dry Matter Production and Quality of Elephantgrass (Pennisetum purpureum Schum.) Cultivar Roxo at Different Cutting Ages}

\begin{abstract}
This experiment was conducted to evaluate the total dry matter (DM) production, leaf/stem ratio, percentage of leaf and stem and nutritive value of the elephantgrass (Pennisetum purpureum Schum.) cultivar Roxo under four cutting ages (40, 60, 80 and 100 days) from July of 1994 to December of 1995 in the wet land region of the Paraíba State. The cultivar was stablished in plots of 3,0 × 5,0 m and plant spacing of $0,70 \times 0,80 \mathrm{~m}$, using a completely randomized design with four replicates. The total dry matter production increased with the cutting ages intervals (quadratic relationship), with the highest production of $30,9 \mathrm{t} / \mathrm{ha}$ at $100 \mathrm{days}$. The percentage of leaf and leaf/stem ratio decreased, while the percentage of stem linearly increased with the increase of the cutting ages. There were a decreased in the crude protein contents and cell content, while the neutral detergent fiber and acid detergent fiber contents increased linearly with the increase of the cutting age.
\end{abstract}

Key Words: percentage of leaf and stem, leaf/stem ratio, nutritive value

\section{Introdução}

Variações na qualidade e produção da forragem, no decorrer do ano, constituem os fatores de maior importância na produtividade do rebanho bovino do Nordeste brasileiro. Uma das alternativas recomendadas para se obter bom equilíbrio entre a disponibilidade e a necessidade de forragem, durante o período de escassez, é o uso de capineiras.

O capim-elefante (Pennisetum purpureum Schum.) destaca-se por sua alta produção de matéria seca (MS) pela unidade de área e pelo equilíbrio nutritivo, sendo cultivado em todo o Brasil, resistindo às condições climáticas desfavoráveis, como seca e frio. Nesse sentido, autores como ALBERTO et al. (1993), ANDRADE (1993), ANDRADE e SALGADO (1992) têm trabalhado com essa espécie, avalian- do sua produtividade e qualidade.

No manejo das capineiras, a freqüência de corte influi no rendimento e na qualidade da forragem colhida. Em geral, o aumento do intervalo de cortes resulta em incrementos na produção de MS, porém, paralelamente, ocorre declínio no valor nutritivo da forragem produzida. Assim, SANTANA et al. (1989), trabalhando com três cultivares de capim-elefante (Cameroon, Mineiro e Napier de Goiás) submetidas a três intervalos de cortes $(4,8$ e 12 semanas) e três alturas de cortes $(0,15$ e $30 \mathrm{~cm})$, verificaram incrementos na produção de MS e porcentagem de colmos e diminuição do teor de proteína bruta $(\mathrm{PB})$ e porcentagem de lâmina foliar quando o intervalo de corte aumentou de 4 para 12 semanas. Concluíram, no entanto, que o intervalo de corte de 8 semanas, associado ao corte da planta ao nível do solo, repre-

\footnotetext{
${ }^{1}$ Parte da Dissertação de Graduação apresentada pelo terceiro autor ao CCA/UFPB como requisito para obtenção do Grau de Zootecnista. 2 Professor do DZ/CCA/UFPB - 58.397-000 - Areia - PB. E. mail: cca@cca.ufpb.br

3 Zootecnista. Aluno do Curso de Mestrado/UFPel.
} 
sentou a melhor combinação para utilização das três cultivares. Em trabalho mais recente, com as mesmas cultivares, SANTANA et al. (1994) verificaram, também, aumentos na produção de MS e declínio nos teores de PB com o aumento do intervalo de cortes de 28 para 84 dias, concordando com os resultados relatados por ACUNHA e COELHO (1994a), para a cultivar Mott, e LAVEZZO et al. (1979 a, b), para a cultivar Roxo. Nessa mesma linha de pesquisa, COSTA e OLIVEIRA (1993), trabalhando com a cultivar Roxo submetida a três idades de corte $(46,61$ e 76 dias), concluíram que a maior produção de MS ocorreu no corte aos 76 dias e o maior teor de PB, aos 45 dias. De modo semelhante, COSTA et al. (1995), TEIXEIRA PRIMO e RODRIGUES (1991), MENDONÇA et al. (1983) e GONÇALVES e COSTA (1987) encontraram aumentos na produção de MS e declínio nos teores de PB de cultivares de capimelefante com o aumento do intervalo entre cortes.

A relação folha/colmo (F/C) é de grande importância do ponto de vista nutritivo e do manejo das espécies forrageiras. Das variações de peso das frações folha e colmo, resultam diferenças entre as gramíneas forrageiras, em que a alta relação $\mathrm{F} / \mathrm{C}$ representa forragem de maior teor de proteína, digestibilidade e consumo. Segundo PASSOS (1994), a qualidade da forragem diminui com a maturação das folhas, pelo aumento do teor de lignina e pela diminuição da relação $\mathrm{F} / \mathrm{C}$ e do teor de $\mathrm{PB}$. Da mesma forma, para ALCÂNTARA (1986), os maiores valores de $\mathrm{PB}$ e digestibilidade encontram-se nas folhas das gramíneas. Assim, o autor considera que a qualidade da forrageira está, em parte, na dependência da quantidade de folhas que possui em relação aos colmos. Nesse sentido, PINTO et al. (1994), avaliando a produção de MS e a relação folha/caule de gramíneas forrageiras tropicais, consideraram, como limite crítico, relação F/C igual a 1,0 para determinar a idade do corte de 42 dias, para capim andropogon (Andropogon gayanus Kunth.) e capim guiné (Panicum maximum Jack.), e 28 dias, para o capim-setária (Setraria anceps Stapf ex Massey.)

As maiores mudanças que ocorrem na composição química das plantas forrageiras são aquelas que acompanham sua maturação. À medida que a planta envelhece, a proporção dos componentes potencialmente digestíveis tendem a diminuir e a de fibras, aumentar. Isso pode ser observado no trabalho de SANTANA et al. (1989), com cultivares de capimelefante, quando se observam redução na percentagem de lâmina foliar e, consequientemente, aumento na percentagem de colmos com o envelhecimento das plantas. Concordando com esse relato, CRUZ FILHO e MONKS (1983) observaram aumentos nos teores de fibra detergente ácido (FDA) da cultivar Cameroon, 39, $0 ; 38,5 ;$ e $38,1 \%$, aos 30 dias, para 40,3; 40,2 ; e 40,2\%, aos 60 dias, e 44,0; 44,2; e 44,0\%, aos 90 dias de idade, quando cortada, respectivamente, a 10,20 e $30 \mathrm{~cm}$ de altura. De forma semelhante, DERESZ (1994), estudando o manejo do capimelefante para produção de leite e carne, observou, aos 30 dias de idade, valores de fibra detergente neutro (FDN) e FDA, respectivamente, de 66,3 e 38,6\%. Esses valores aumentaram para 68,2 e $42,5 \%$ para FDN e FDA, respectivamente, quando manejada com 45 dias de idade.

Em função do crescimento da área cultivada pelos produtores da região e visando um manejo mais adequado para a cultivar, o presente trabalho teve como objetivo avaliar o efeito de quatro idades de corte sobre o rendimento de MS, a relação F/C e o valor nutritivo da forragem do capim-elefante 'Roxo' no Brejo Paraibano.

\section{Material e Métodos}

O experimento foi realizado em área de pastagem do Departamento de Zootecnia do CCA/UFPB, no período de julho de 1994 a dezembro de 1995, em um solo classificado como Podzólico Vermelho-Amarelo Equivalente Eutrófico, com horizonte A proeminente, textura argilosa, fase floresta subperenifólia, relevo forte ondulado (BRASIL, 1972), cuja análise química apresentou os seguintes resultados: $\mathrm{pH}=4,7 ; \mathrm{P}=18,0$ e $\mathrm{K}=144,0 \mathrm{mg} / \mathrm{dm} 3 ; \mathrm{MO}=10,2 \mathrm{~g} / \mathrm{dm}^{3} ; \mathrm{Al}^{+++}=0,29 \mathrm{e}$ $\mathrm{Ca}^{++} \mathrm{Mg}^{++}=2,00 \mathrm{cmol}_{\mathrm{c}} / \mathrm{dm}^{3}$. A precipitação total ocorrida durante o período de avaliação (janeiro a dezembro de 1995) foi de $1245,6 \mathrm{~mm}$, com temperatura média mensal de $23,1^{\circ} \mathrm{C}$ e umidade relativa mensal média de $81,2 \%$.

Foi utilizado o delineamento inteiramente casualizado com a cultivar Roxo de capim-elefante (Pennisetum purpureum Schum.) submetida a quatro intervalos de corte $(40,60,80$ e 100 dias) e quatro repetições, perfazendo um total de 16 parcelas com 3,0 x 5,0 m cada e área útil de 2,10 x 4,0 m.

Para correção do pH do solo foi aplicado calcário dolomítico nas parcelas, na proporção de $3000 \mathrm{~kg} / \mathrm{ha}$ e, em $28 / 07 / 94$, foi realizado o plantio, em covas espaçadas de $0,70 \times 0,80 \mathrm{~cm}$, com estacas contendo três gemas, de maneira que somente uma gema ficasse acima do nível do solo. Por ocasião do plantio, 
colocou-se na cova o equivalente a $10 \mathrm{~kg} / \mathrm{ha}$ de $\mathrm{N}$ na forma de sulfato de amônio, $30 \mathrm{~kg} / \mathrm{ha}$ de $\mathrm{P}_{2} \mathrm{O}_{5}$ na forma de superfosfato triplo e $20 \mathrm{~kg} / \mathrm{ha}$ de $\mathrm{K}_{2} \mathrm{O}$ na forma de cloreto de potássio. Em 12/09/94, foi feita adubação de cobertura com $40 \mathrm{~kg} / \mathrm{ha}$ de N. Em 04/01/95, realizou-se o corte de uniformização, no nível do solo, para iniciar as avaliações experimentais. Por ocasião deste corte, bem como após cada corte de avaliação, foi aplicada adubação de reposição em superfície, equivalente a $30 \mathrm{~kg} / \mathrm{ha}$ de $\mathrm{N}, 10 \mathrm{~kg} / \mathrm{h}$ a de $\mathrm{P}_{2} \mathrm{O}_{5}$ e $10 \mathrm{~kg} / \mathrm{ha}$ de $\mathrm{K}_{2} \mathrm{O}$. Após cada corte, foram efetuadas capinas nas parcelas experimentais.

Para determinar a produção total de MS, a porcentagem de folhas e colmos e a relação $\mathrm{F} / \mathrm{C}$, foram realizados cortes rente ao solo a intervalos de 40 (9 cortes), 60 (6 cortes), 80 (4 cortes) e 100 dias ( 3 cortes), sendo os primeiros cortes por idade realizados, respectivamente, em 13/02, 05/03, 22/03 e 14/04/95.

A produção de MS foi determinada mediante corte e pesagem das plantas da área útil das parcelas. Foram retirados, ao acaso, três a quatro perfilhos, cortados em pedaços de $2 \mathrm{a} 3 \mathrm{~cm}$, colocados em sacos de papel, pesados e levados à estufa a $65^{\circ} \mathrm{C}$ até peso constante. Após a secagem, foram separadas as frações folha (lâmina e bainha) e colmo, pesadas separadamente, moídas juntas e acondicionadas em frascos de vidro. A produção total de MS por idade resultou da soma das produções obtidas em cada corte.

As análises químicas de proteína bruta $(\mathrm{PB})$, fibra em detergente neutro (FDN) e fibra em detergente ácido (FDA), corrigidas para a MS, a $105^{\circ} \mathrm{C}$, foram realizadas segundo SILVA (1990). As análises de PB foram realizadas em amostras de todos os cortes em todas as idades, enquanto as análises de FDN e FDA foram realizadas nos primeiros, últimos e no corte intermediário, em cada idade, e apresentadas como média dos tratamentos. O conteúdo celular (CC) foi calculado subtraindo-se de 100 a porcentagem de FDN das amostras. As variáveis em estudo foram submetidas a análises de variância e regressão, usando-se o programa estatístico ESTAT, versão 2.0.

\section{Resultados e Discussão}

\section{Produção de matéria seca}

Verificou-se efeito quadrático significativo $(\mathrm{P}<0,05)$ para a produção total de MS do capimelefante 'Roxo', em função dos intervalos de corte $\left(\hat{Y}=10,73+0,2585 X-0,0006 X^{2}\right)$, obtendo-se res- posta menos acentuada a partir de 60 dias de idade. A produção de MS obtida aos 40 dias correspondeu a $63,1 \%$ daquela verificada aos 100 dias e a $75,9 \%$ das obtidas aos 60 e 80 dias de idade.

A tendência de aumento verificada para a produção de MS (Tabela 1), com o aumento do intervalo de corte, concorda com os resultados observados por COSTA e OLIVEIRA (1993), trabalhando com o capim-elefante cultivar Roxo, e ACUNHA e COELHO (1994a), com a cultivar Mott, que encontraram as maiores produções de MS com os maiores intervalos entre cortes. Observa-se, ainda, na Tabela 1 que a porcentagem de folhas diminuiu acentuadamente acima dos 60 dias, atingindo 51,4\% aos 80 dias de idade. Considerando-se que os maiores valores de PB e digestibilidade encontram-se nas folhas, o corte para utilização da forragem na alimentação animal acima desta idade deve resultar em queda na qualidade, devido ao acréscimo da fração colmo na forragem produzida. Esta observação concorda com SANTOS (1996), que relata a idade de 60 a 70 dias como a melhor para o uso do capim-elefante com altos teores de açúcares.

Observa-se na Tabela 3 que a porcentagem de colmos aumentou de forma linear $\left(\mathrm{R}^{2}=0,98\right)$ com a idade do capim-elefante, ficando evidenciada a importância desta fração na produção total de MS.

Percentagem de folhas, colmos e relação folha/colmo

As respostas foram lineares negativas para a porcentagem de folhas e a relação F/C e linear positiva para a porcentagem de colmos, em função das idades de corte do capim-elefante 'Roxo' (Tabela 3). Estes dados concordam com os relatados por SANTANA et al. (1989), trabalhando com outras cultivares de capim-elefante como Cameroon, Mineiro e Napier de Goiás, que também verificaram redução na porcentagem de folhas e relação folha/colmo, com consequiente acréscimo na porcentagem de colmos, com o aumento da idade das plantas.

A relação folha/colmo é de grande importância tanto para a nutrição animal como para o manejo das plantas forrageiras. Alta relação folha/colmo significa forragem de maior teor protéico, digestibilidade e consumo, capaz de atender às exigências nutricionais dos animais. Segundo ALCÂNTARA (1986), os maiores valores de PB e digestibilidade encontramse nas folhas das gramíneas, estando, portanto, a qualidade da planta forrageira intimamente relacionada com a sua relação folha/colmo. O corte aos 40 
Tabela 1 - Produção total de matéria seca (MS), percentagem de folhas, colmos e relação folha/colmo (R F/C) nas idades de cortes do capim-elefante 'Roxo'

Table 1 - Total dry matter (DM) production, percentage of leaf, stem and leaf/stem ratio ( $L / S R)$ in the cutting ages of the elephantgrass 'Roxo'

\begin{tabular}{lcccc}
\hline Idade (dias) & MS & Folhas & Colmos & R F/C \\
Age (days) & $D M$ & Leaf & Stem & L/S R \\
\hline & t/ha & -------------- & 2,9 \\
40 & 19,5 & 74,4 & 25,6 & 1,7 \\
60 & 25,7 & 62,9 & 37,1 & 1,1 \\
80 & 25,7 & 51,4 & 48,6 & 0,8 \\
100 & 30,9 & 45,2 & 54,8 & \\
\hline
\end{tabular}

Tabela 2 - Teor médio de proteína bruta (PB), conteúdo celular (CC), fibra em detergente neutro (FDN) e fibra em detergente ácido (FDA) do capimelefante 'Roxo'

Table 2 - Average content of crude protein (CP), cellular content (CC), neutral detergent fiber (NDF) and acid detergent fiber (ADF) of the elephantgrass 'Roxo'

\begin{tabular}{lcccc}
\hline Idade (dias) & PB & CC & FDN & FDA \\
Age (days) & $C P$ & $C C$ & $N D F$ & $A D F$ \\
\hline & t/ha & -- & 65,7 & 36,5 \\
60 & 13,8 & 34,3 & 71,3 & 41,3 \\
80 & 8,6 & 28,7 & 72,5 & 44,4 \\
100 & 7,4 & 27,5 & 77,0 & 48,8 \\
\hline
\end{tabular}

Tabela 3 - Regressão da produção total de matéria seca (MS), percentagem de folhas, colmos, relação folha/colmo (R F/C) e teores médios de proteína bruta (PB), conteúdo celular (CC), fibra em detergente neutro (FDN) e fibra em detergente ácido (FDA) em função da idade do corte do capim-elefante 'Roxo'

Table 3 - Regression equations of the total dry matter (DM) production, percentage of leaf, stem and leaf/ stem ratio $(L / S R)$ and average contents of crude protein $(C P)$, cellular content $(C C)$, neutral detergent fiber (NDF) and acid detergent fiber (ADF) as a function of cutting ages of the elephantgrass "Roxo'

\begin{tabular}{llcc}
\hline $\begin{array}{l}\text { Variável } \\
\text { Variable }\end{array}$ & \multicolumn{1}{c}{$\begin{array}{c}\text { Regressão } \\
\text { Regression }\end{array}$} & $\begin{array}{c}\text { Nível de significância } \\
\text { Significancelevel }\end{array}$ & $\mathrm{R}^{2}$ \\
\hline MS (t/ha) DM(t/ha) & $\hat{\mathrm{Y}}=10,73+0,2585 \mathrm{X}-0,0006 \mathrm{X}^{2}$ & $*$ & 0,90 \\
$\%$ folhas (\%leaf) & $\hat{\mathrm{Y}}=93,16-0,4955 \mathrm{X}$ & $* *$ & 0,98 \\
$\%$ colmos (\% stems) & $\hat{\mathrm{Y}}=6,84+0,4955 \mathrm{X}$ & $* *$ & 0,98 \\
R F/C (L/SR) & $\hat{\mathrm{Y}}=4,04-0,0345 \mathrm{X}$ & $*$ & 0,92 \\
$\%$ PB $(\% C P)$ & $\hat{\mathrm{Y}}=28,205-0,4628 \mathrm{X}+0,0024 \mathrm{X}^{2}$ & $* *$ & 0,97 \\
$\%$ CC $(\% C C)$ & $\hat{\mathrm{Y}}=40,66-0,1755 \mathrm{X}$ & $*$ & 0,95 \\
$\%$ FDN $(\% N D F)$ & $\hat{\mathrm{Y}}=59,34+0,1755 \mathrm{X}$ & $*$ & 0,95 \\
$\%$ FDA $(\% A D F)$ & $\hat{\mathrm{Y}}=28,75+0,2000 \mathrm{X}$ & $* *$ & 0,99 \\
\hline
\end{tabular}

* Efeito linear/quadrático significativo $(\mathrm{P}<0,05)$

** Efeito linear/quadrático muito significativo $(P<0,01)$.

* Significant linear/quadratic effect $(P<.05)$.

** Significant linear/quadratic effect $(P<.01)$. 
dias apresentou a maior relação F/C $(2,9)$, apesar de ter apresentado a menor produção total de MS (Tabela 1). Este fato pode ser explicado pela menor percentagem de colmos $(25,6 \%)$ verificado para esta idade. A menor relação F/C ocorrida aos 100 dias $(0,8)$, provavelmente, decorreu da maior porcentagem de colmos, com maior desenvolvimento das plantas e alongamento dos colmos mais acentuado. Segundo PINTO et al. (1994), alta relação folha/ colmo confere à gramínea melhor adaptação ao pastejo ou tolerância ao corte, por representar um momento de desenvolvimento fenológico em que os meristemas apicais se apresentam mais próximos ao solo e, portanto, menos vulneráveis à destruição.

$\mathrm{O}$ decréscimo verificado na relação $\mathrm{F} / \mathrm{C}$, com o aumento da idade do corte (Tabela 1), está de acordo com os dados encontrados para a cultivar Mott por ACUNHA e COELHO (1994b), que observaram relação linear negativa para a relação folha/colmo, à medida que o intervalo de corte aumentou de 28 para 140 dias. Considerando-se como limite crítico uma relação folha/colmo igual a 1,0, associando-se quantidade e qualidade da forragem produzida, observase, na Tabela 1, que este limite foi atingido praticamente aos 80 dias de idade $(1,1)$.

\section{Valor nutritivo}

A análise de regressão revelou efeito significativo $(\mathrm{P}<0,01)$ dos intervalos de corte sobre os teores de $\mathrm{PB}$ na MS do capim-elefante 'Roxo'. Verificaram-se reduções de maneira quadrática nos teores de $\mathrm{PB}$, com o aumento dos intervalos de corte (Tabela 3), obtendo-se o maior teor $(13,8 \%)$ aos 40 dias e o menor $(6,1 \%)$ aos 100 dias (Tabela 2). Estes dados concordam com os verificados por ACUNHA e COELHO (1994a), SANTANA et al. (1989) e SANTANA et al. (1994), que, trabalhando com outras cultivares de capim-elefante, também observaram os maiores teores de PB nos menores intervalos de corte. Considerando-se que o nível mínimo de proteína nos alimentos, para que ocorra adequada fermentação ruminal, deve ser de 7\% (MINSON, 1984), observa-se que somente a idade de 100 dias não satisfaz esta exigência.

As equações de regressão mostraram que, com o aumento da idade do corte, ocorrem redução linear para os teores de conteúdo celular e acréscimo linear nos teores de FDN e FDA (Tabela 3), provocando, dessa maneira, diminuição do valor nutritivo da forragem, uma vez que as frações solúveis são inversamente proporcionais às frações fibrosas quando se aumenta a idade das plantas. SILVEIRA et al. (1974), trabalhando com o capim-elefante cultivar 'Napier', também, verificaram aumento nas partes fibrosas da forragem com o envelhecimento da gramínea.

Os baixos teores de PB e conteúdo celular e os altos de FDN e FDA, encontrados aos 100 dias de idade de capim-elefante 'Roxo', devem estar relacionados com a sua baixa relação $\mathrm{F} / \mathrm{C}(0,8)$ verificada nesta idade. $O$ potencial de uma planta forrageira não deve ser avaliado levando-se em consideração somente os aspectos quantitativos. Os dados obtidos neste trabalho mostram que a forragem colhida aos 100 dias apresentou a maior produção total de MS, apresentando, porém, os menores teores de $\mathrm{PB}$ e conteúdo celular e os maiores de FDN e FDA, mostrando baixa qualidade para grande quantidade de MS produzida. Estas observações corroboram com os dados registrados na literatura de que o capim-elefante, quandoé mais novo, apresenta equilíbrio nutritivo.

\section{Conclusões}

Considerando-se a análise global dos resultados obtidos, visando associar a quantidade com a qualidade da forragem produzida, a melhor faixa de idade de corte, para a utilização do capim-elefante 'Roxo', é de 60 a 80 dias.

\section{Referências Bibliográficas}

ACUNHA, J.B.V., COELHO, R.W. Influência da altura e freqüência de corte no capim-elefante anão. I. Produção de matéria seca e proteína bruta. In: REUNIÃO ANUAL DA SOCIEDADE BRASILEIRA DE ZOOTECNIA, 31, Maringá, 1994. Anais... Maringá: SBZ, 1994a, p.330.

ACUNHA, J.B.V., COELHO, R.W. Influência da altura e frequiência de corte no capim-elefante anão. II. Relação folha/ colmo e área foliar. In: REUNIÃO ANUAL DA SOCIEDADE BRASILEIRA DE ZOOTECNIA, 31, Maringá, 1994. Anais ... Maringá: SBZ, 1994b, p.331.

AlBerto, G., PORTELA, J.S., OLIVEIRA, O.L.P. 1993. Efeito de adição de grãos de sorgo moído e do murchamento sobre a qualidade de silagens de capim-lefante (Pennisetum purpureum Schum.). R. Soc. Bras. Zootec., 22(1):1-11.

ALCÂNTRA, P.B. Origem das brachiarias e suas características morfológicas de interesse forrageiro: In: ENCONTRO PARA DISCUSSÃO SOBRE CAPINS DO GÊNERO BRACHIARIA, Nova Odessa, 1986. Resumos...Nova Odessa: Instituto de Zootecnia, 1986, p.1-14.

ANDRADE, I.F. 1993. Efeito da época de vedação na produção e valor nutritivo do capim-elefante (Pennisetum purpureum Schum.) cv. Mineirão. R. Soc. Bras. Zootec., 22(1):53-63.

ANDRADE, I.F., SALGADO, J.G.F. 1992. Efeito da época de vedação de capim-elefante (Pennisetum purpureum Schum.) cv. Cameroon sobre sua produção e valor nutritivo. R. Soc. Bras. Zootec., 21(4):637-646. 
BRASIL. Ministério da Agricultura. 1972. Equipe de Pedologia e fertilidade do solo. Divisão de Agrologia-SUDENE. Levantamento Exploratório-Reconhecimento de solos do Estado da Paraíba. Rio de Janeiro. 670p (Boletim Técnico, 15).

COSTA, N. L., MAGALHÃES, J. A., PEREIRA, R. G. A. Efeito de regimes de cortes sobre a produção de forragem e composição química do capim-elefante (Pennisetum purpureum Schum.) In: REUNIÃO ANUAL DA SOCIEDADE BRASILEIRA DE ZOOTECNIA, 32, Brasília, 1995. Anais... Brasília: SBZ: 1995. p.40-42.

COSTA, R.O., OLIVEIRA, M.E. Avaliação do capim-elefante submetido a três épocas de corte. In: REUNIÃO DE PESQUISAS DO CCA, 3, Teresina, 1993. Anais... Teresina: CCA/UFPI, 1993. p.295-303.

CRUZ FILHO, A.B., MONKS, P.L. Efeito da freqüência e da altura de corte sobre a produção e qualidade da forragem em capim-elefante cv. Cameron. In: REUNIÃO ANUAL DA SOCIEDADE BRASILEIRA DE ZOOTECNIA, 20, Pelotas, 1983. Anais ... Pelotas: SBZ, 1983. p.310.

DERESZ, F. Manejo de pastagem de capim-elefante para a produção de leite e carne. In: SIMPÓSIO SOBRE CAPIM ELEFANTE, 2, Juiz de Fora, 1994. Anais ... Juiz de Fora: EMBRAPA/CNPGL, 1994. p.116-138.

GONÇALVES, C.A., COSTA, N.L. Curva de crescimento e valor nutritivo do capim-elefante cv. Cameroon em Rondônia. In: REUNIÃO ANUAL DA SOCIEDADE BRASILEIRA DE ZOOTECNIA, 18, Goiânia, 1987. Anais ... Goiânia: SBZ, 987. p.188.

LAVEZZO,W., SILVEIRA, A.C., GONÇALVES, D.A. et al. Capim-elefante (Pennisetum purpureum Schum.) cv. Roxo. II. Efeito da idade ao $1^{\circ}$ corte sobre a produção de MS e sobre algumas características morfológicas. In: REUNIÃO ANUAL DA SOCIEDADE BRASILEIRA DE ZOOTECNIA, 16, Curitiba, 1979. Anais ... Curitiba: SBZ, 1979a, p.410.

LAVEZZO,W., SILVEIRA, A.C., GONÇALVES, D.A. et al.Capimelefante (Pennisetum purpureum Schum.) cv. Roxo. I. Efeito da idade ao $1^{\circ}$ corte sobre a composição bromatológica e teores de macro e micro elementos. In: REUIÃO ANUAL DA SOCIEDADE BRASILEIRA DE ZOOTECNIA, 16, Curitiba, 1979. Anais... Curitiba: SBZ, 1979b, p.409.

MENDONÇA, J.F.B., ROCHA, G.P., OLIVEIRA, J.P. et al. Composição química e rendimento do capim-elefante (Pennisetum purpureum Schum.) cv. Cameroon. In: REUNIÃO ANUAL DA SOCIEDADE BRASILEIRA DE ZOOTECNIA, 20, Pelotas, 1983. Anais ... Pelotas: SBZ, 1983. p.318.
MINSON, D.J. 1984. Effects of chemical and physical composition of herbaje eaten upon intake. In: HACKER, J.B. (Ed.) Nutritional limits to animal production from pasture. Farnham Royal: CAB. p.167-182.

PASSOS, L.P. Estado do conhecimento sobre a fisiologia do capimelefante. In: SIMPÓSIO SOBRE CAPIM-ELEFANTE, 2, Juiz de Fora, 1994. Anais... Juiz de fora: EMBRAPA/CNPGL, 1994. p.12-43.

PINTO, J.C., GOMIDE, J.A., MAESTRI, M. 1994. Produção de matéria seca e relação folha/caule de gramíneas forrageiras tropicais, cultivadas em vasos, com duas doses de nitrogênio. R. Soc. Bras. Zootec., 23(3):313-326.

SANTANA, J.P., PEREIRA, J.M., ARRUDA, N.G. et al. 1989. Avaliação de cultivares de capim-elefante (Pennisetum purpureum Schum.) no Sul da Bahia. I. Agrossistema Cacaueiro. R. Soc. Bras. Zootec., 18(3):273-282.

SANTANA, J.R., PEREIRA, J.M., RUIZ, M.A.M. 1994. Avaliação de cultivares de capim-elefante (Pennisetum purpureum Schum.) no Sudoeste da Bahia. II. Agrossistema Itapetinga. $R$. Soc. Bras. Zootec., 23(4):507-517.

SANTOS, E.A. Níveis de dejetos de suínos na silagem de capimelefante (Pennisetum purpureum Schum.) Areia: CCA/UFPB, 1996.49p. Monografia (GraduaçãoemZootecnia) - Universidade Federal da Paraíba, 1996.

SILVA, D.J. 1990. Análise de alimentos (métodos químicos $e$ biológicos). 2 ed. Viçosa: UFV, Impr. Univ. 165p.

SILVEIRA, A.C., TOSI, H.,FARIA, V.P. 1974. Efeito da maturidade sobre a composição bromatológica do capim Napier. $R$. Soc. Bras. Zootec., 3(2):158-171.

TEIXEIRA PRIMO, A., RODRIGUES, R.C. Avaliação de germoplasma de capim-elefante e/ou híbridos de capim elefante/ milheto sob diferentes frequiências de corte, em terras baixas In: REUNIÃO ANUAL DA SOCIEDADE BRASILEIRADE ZOOTECNIA, 28, João Pessoa, 1991. Anais ... João Pessoa: SBZ, 1991. p.74.

Recebido em: 06/11/98

Aceito em: 02/06/99 